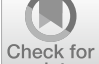

Check for

updates

Cite as

Nano-Micro Lett.

(2020) 12:62

Received: 25 November 2019

Accepted: 23 January 2020

Published online: 22 February 2020

(C) The Author(s) 2020

\section{Ultra-sensitive Nanoprobe Modified with Tumor Cell Membrane for UCL/MRI/PET Multimodality Precise Imaging of Triple-Negative Breast Cancer}

\author{
Hanyi Fang ${ }^{1,2}$, Mengting Li ${ }^{1,2}$, Qingyao Liu ${ }^{1,2}$, Yongkang Gai ${ }^{1,2}$, Lujie Yuan ${ }^{1,2}$, \\ Sheng Wang ${ }^{3}$, Xiao Zhang ${ }^{1,2}$, Min Ye ${ }^{1,2}$, Yongxue Zhang ${ }^{1,2}$, Mingyuan $\mathrm{Gao}^{4}$, Yi Hou ${ }^{5}$, \\ Xiaoli $\operatorname{Lan}^{1,2} \bowtie$ \\ $\triangle$ Yi Hou,houyi@iccas.ac.cn; Xiaoli Lan, xiaoli_lan@hust.edu.cn \\ 1 Department of Nuclear Medicine, Union Hospital, Tongji Medical College, Huazhong University \\ of Science and Technology, Wuhan 430022, People's Republic of China \\ 2 Hubei Province Key Laboratory of Molecular Imaging, Wuhan 430022, People's Republic of China \\ 3 School of Pharmacy, Tongji Medical College, Huazhong University of Science and Technology, \\ Wuhan 430030, People's Republic of China \\ 4 Center for Molecular Imaging and Nuclear Medicine, State Key Laboratory of Radiation Medicine \\ and Protection, School for Radiological and Interdisciplinary Sciences (RAD-X), Soochow University, \\ Suzhou 215123, Jiangsu, People's Republic of China \\ 5 Key Laboratory of Colloid, Interface and Chemical Thermodynamics, Institute of Chemistry, Chinese \\ Academy of Sciences, Beijing 100190, People's Republic of China
}

\title{
HIGHLIGHTS
}

- A biomimetic nanoprobe was built with cancer cell membrane-coated and $\mathrm{Gd}^{3+}$-doped upconversion nanoparticles.

- The nanoprobe could be applied to in vivo UCL/MRI/PET multimodality precise imaging and successfully differentiated MDA-MB-231 tumor models through in vivo tri-modality imaging, which may be used for breast cancer molecular classification.

\begin{abstract}
Triple-negative breast cancer (TNBC) is a subtype of breast cancer in which the estrogen receptor and progesterone receptor are not expressed, and human epidermal growth factor receptor 2 is not amplified or overexpressed either, which make the clinical diagnosis and treatment very challenging. Molecular imaging can provide an effective way to diagnose TNBC. Upconversion nanoparticles (UCNPs), are a promising new generation of molecular imaging probes. However, UCNPs still need to be improved for tumor-targeting ability and biocompatibility.

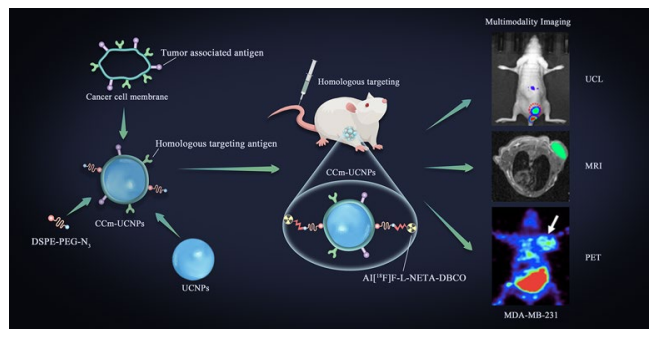
This study describes a novel probe based on cancer cell membrane-coated upconversion nanoparticles (CCm-UCNPs), owing to the low immunogenicity and homologous-targeting ability of cancer cell membranes, and modified multifunctional UCNPs. This probe exhibits excellent performance in breast cancer molecular classification and TNBC diagnosis through UCL/MRI/PET tri-modality imaging in vivo. By using this probe, MDA-MB-231 was successfully differentiated between MCF-7 tumor models in vivo. Based on the tumor imaging and molecular classification results, the probe is also expected to be modified for drug delivery in the future, contributing to the treatment of TNBC. The combination of nanoparticles with biomimetic cell membranes has the potential for multiple clinical applications.
\end{abstract}

KEYWORDS Triple-negative breast cancer; Molecular classification; Multimodality imaging; Cancer cell membranes; Upconversion 


\section{Introduction}

Breast cancer (BC) is a malignant disease leading to approximately two million new cases (11.6\%) and 620,000 deaths worldwide in 2018 [1]. It is also a highly heterogeneous disease requiring molecular classification for treatment and prognosis [2]. Triple-negative breast cancer (TNBC) is a subtype of $\mathrm{BC}$ in which the estrogen receptor (ER) and progesterone receptor (PR) are not expressed, and the human epidermal growth factor receptor 2 (HER2) is not amplified or overexpressed either [3]. At present, the diagnosis of TNBC mostly relies on tissue biopsy, which is affected by sampling error and invasiveness [4]. Therefore, the clinical diagnosis of TNBC remains challenging.

Molecular imaging can in principle provide powerful tools for identifying cancers with greatly improved specificity and sensitivity [5], and functional inorganic nanoparticles have shown great potential as imaging probes owing to the intrinsic physical properties of inorganic particles apart from the well-known enhanced permeation and retention effect of tumors for nano-objects. Among different kinds of functional inorganic nanoparticles, upconversion nanoparticles (UCNPs) are superior as light-emitting, and rareearth ions can facilely be combined with paramagnetic ones such as $\mathrm{Gd}^{3+}$, for simultaneously visualizing tumors through upconversion luminescence (UCL) [6] and magnetic resonance imaging (MRI) [7, 8]. Besides, they also provide an excellent platform to further combine photoacoustic imaging (PAI) [9], single-photon emission computed tomography (SPECT) [10], and positron emission tomography (PET) imaging [11], with above imaging modalities.

Every imaging modality has its intrinsic advantages and disadvantages. To acquire multi-dimensional biological information, rationally combining different imaging modalities is essentially required, thus receiving increasing attention [7, 11-13]. The UCL of rare-earth nanoparticles typically requires near-infrared (NIR) lasers of 800 or $980 \mathrm{~nm}$ as excitation source which can reach deeper tissues and avoid autofluorescence of the biological tissues [14], particularly suitable for $\mathrm{BC}$ detection. The excellent photostability, lack of photoblinking, and ultra-sensitive detection of upconverting visible emissions make UCNPs promising for bioimaging [14], even for real-time imaging [15, 16]. MRI can provide high spatial resolution of soft tissues [17]. PET exhibits high sensitivity and unlimited detection depth [13]. UCNPs can well combine these strengths by being properly incorporated with $\mathrm{Gd}^{3+}$ and SPECT/PET nuclides [7, 11, 12]. However, the nanoparticles are prone to stimulate the mononuclear phagocyte system, shortening their blood residence time [18]. Therefore, different types of surface engineering approaches have been developed by modifying the nanoparticles with either artificial materials or natural substances. Poly(ethylene glycol) (PEG) [19] and cell membranes [15, 20, 21] are two representative examples of the aforementioned approaches. Recently, cell membranes such as the erythrocyte membrane [22-24], platelet membrane [25-27], and cancer cell membrane [16], have been gaining increasing attention. In comparison with polymer coating, cell membranes present low immunogenicity and may provide homologous-targeting ability if cancer cell membrane $(\mathrm{CCm})$ is adopted [12, 16, 28].

In this study, we used the cancer cell membrane of MDAMB-231, a kind of TNBC cell, to modify $\mathrm{Gd}^{3+}$-doped upconversion nanoparticles $\mathrm{NaGdF}_{4}: \mathrm{Yb}, \mathrm{Tm} @ \mathrm{NaGdF}_{4}$ $\left(\mathrm{CCm}_{231}\right.$-UCNPs) for in vivo UCL/MRI/PET tri-modality tumor imaging of $\mathrm{BC}$ and further differentiate between breast cancer subtypes of MDA-MB-231 and MCF-7 to demonstrate the potential of CCm-UCNPs in BC molecular classification (Scheme 1).

\section{Materials and Methods}

\subsection{Materials}

UCNPs $\left(\mathrm{NaGdF}_{4}: \mathrm{Yb}, \mathrm{Tm} @ \mathrm{NaGdF}_{4}\right)$ were supplied by Gao's research group [10]. Dulbecco's modified Eagle medium (DMEM), RPMI-1640 medium, phosphate buffer saline (PBS), trypsin and ethylenediaminetetraacetic acid (EDTA), and penicillin-streptomycin were purchased from Gibco Life Technologies (Gaithersburg, MD, USA). Fetal bovine serum (FBS) was purchased from ScienCell (Carlsbad, CA, USA). Leibovitz's L15 medium, 4',6-diamidino-2-phenylindole (DAPI), paraformaldehyde, and Cell Counting Kit-8 (CCK8) were purchased from Boster Biotechnology (Wuhan, China). 1, 2-Distearoyl-sn-glycero-3-phosphoethanolamine$\mathrm{N}-[\mathrm{Cy} 5$ (polyethylene glycol)-2000] (DSPE-PEG-Cy5), dibenzocyclooctyne (DBCO), and 1, 2-distearoyl-sn-glycero-3-phosphoethanolamine- $\mathrm{N}$-[azido (polyethylene glycol)-2000] (DSPE-PEG-N ${ }_{3}$ ) were purchased from SigmaAldrich (St. Louis, MO, USA). All of the aqueous solutions 


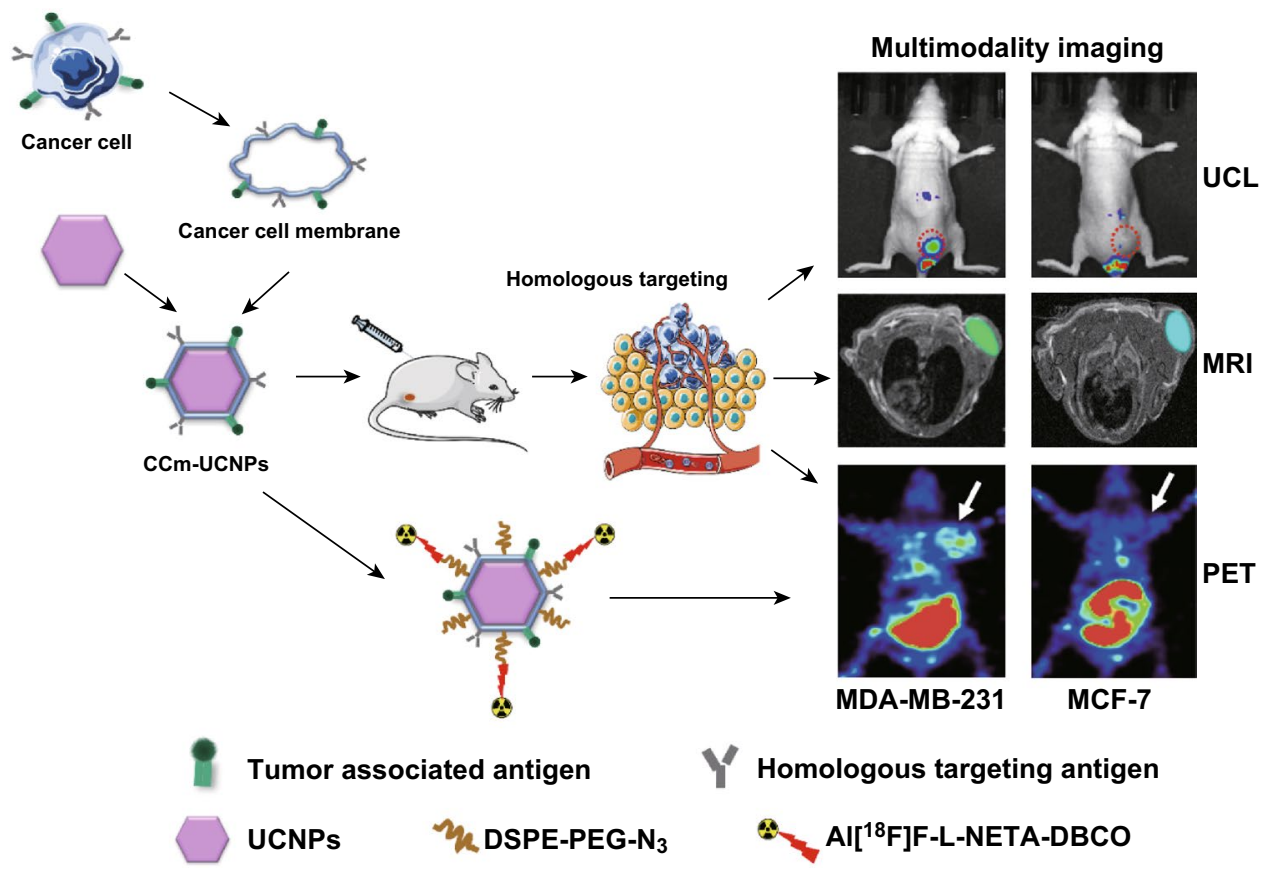

Scheme 1 Illustration of the cancer cell membrane-coated $\mathrm{Gd}^{3+}$-doped upconversion nanoparticles (CCm-UCNPs) used for differentiating between MDA-MB-231 and MCF-7 tumor-bearing mice models by homologous-targeting multimodality imaging, including UCL, MRI, and PET. None of the mice shown in figure was the same mouse

were prepared using deionized (DI) water purified with a purification system. The other reagents used in this work were purchased from Aladdin-Reagent (Shanghai, China).

\subsection{Preparation of Cancer Cell Membranes}

Cancer cell membrane-derived vesicles $(\mathrm{CCm})$ were prepared according to the previous report [12, 16, 29]. MDAMB-231 human breast cancer cells were maintained in DMEM supplemented with $10 \%$ FBS and $1 \%$ penicillin-streptomycin. To harvest membranes, cancer cells were grown in T-175 culture flasks to full confluence and detached with $2 \mathrm{mM}$ EDTA in PBS and washed in PBS three times by centrifuging at $1000 \mathrm{rpm}$ for $4 \mathrm{~min}$. The cells were suspended in a hypotonic lysing buffer consisting of $20 \mathrm{mM}$ Tris- $\mathrm{HCl}, 10 \mathrm{mM} \mathrm{KCl}, 2 \mathrm{mM} \mathrm{MgCl}{ }_{2}$, and 1 EDTA-free mini protease inhibitor tablet per $10 \mathrm{~mL}$ of solution and disrupted at $4{ }^{\circ} \mathrm{C}$ overnight. The entire solution was ultrasonically dispersed by an ultrasonic homogenizer (Scientz-IID, Ningbo Scientz Biotechnology Co., Ltd., Ningbo, China), before spinning down at $3200 \mathrm{~g}$ for $5 \mathrm{~min}$. The supernatants were saved while the pellet was resuspended in hypotonic lysing buffer and dispersed by ultrasound again. The supernatants were pooled and centrifuged at 20,000 $\mathrm{g}$ for $20 \mathrm{~min}$, after which the pellet was discarded and the supernatant was centrifuged again at $100,000 \mathrm{~g}$ for $1 \mathrm{~h}$ using an ultra-speed centrifuge (Optima XPN-100 Ultracentrifuge, Beckman Coulter, Miami, FL, USA). The pellet containing the plasma membrane material was then washed once with $10 \mathrm{mM}$ Tris- $\mathrm{HCl}$ and $1 \mathrm{mM}$ EDTA. The final pellet was collected and used as purified cancer cell membranes for subsequent experiments.

\subsection{Characterization of Cancer Cell Membrane Protein}

SDS-PAGE gel electrophoresis displayed for protein characterization. All samples were prepared at a final protein concentration of $1 \mathrm{mg} \mathrm{mL}^{-1}$ in loading buffer as measured by a bicinchoninic acid (BCA) assay. $\mathrm{CCm}_{231}$-UCNPs were purified by centrifugation at $13,000 \mathrm{rpm}$ to pellet the coated particles but not free vesicles or protein. The mixture of samples and loading buffer with the volume ratio of $4: 1$ was heated to $100{ }^{\circ} \mathrm{C}$ for $10 \mathrm{~min}$, and the mixture of samples and loading buffer with the volume ratio of 3:1 was heated to $37^{\circ} \mathrm{C}$ for $30 \mathrm{~min}$. The denatured sample was loaded into each well in an Electrophoresis System (Cat \#DYZC-24DN, 
Beijing Liuyi Biotechnology Co., Ltd., Beijing, China) based on the manufacturer's instructions. Protein staining was accomplished using 0.05\% Coomassie Brilliant Blue R-250, $30 \%$ methanol, and $10 \%$ acetic acid for $3 \mathrm{~h}$ and destained in $30 \%$ methanol and $10 \%$ acetic acid and stored at room temperature. For western blot analysis, the protein was transferred to polyvinylidene fluoride (PVDF) membranes (Millipore Cat\#IPVH00010, Millipore, Inc. Bedford, MD, USA) using an XCell II Blot Module (Invitrogen, Carlsbad, CA, USA) in NuPAGE transfer buffer (Invitrogen, Carlsbad, CA, USA) per manufacturer's instructions. Membranes were probed using antibodies against EGFR, $\mathrm{Na}^{+} / \mathrm{K}^{+}$-ATPase, histone $\mathrm{H} 3$, and glyceraldehyde 3-phosphate dehydrogenase along with either horseradish peroxidase (HRP)-conjugated anti-mouse IgG (Poly4053, Biolegend, San Diego, CA, USA) or anti-rabbit IgG (Poly4064, Biolegend). Films were developed using ECL western blotting substrate (Pierce Biotechnology, Rockford, IL, USA) and developed with the Mini-Medical/90 Developer (ImageWorks, Culver City, CA, USA).

\subsection{In Vitro and Cell Cytotoxicity Assay}

1, 2-Distearoyl-sn-glycero-3-phosphoethanolamine-N(polyethylene glycol) 2000-Cy5 (DSPE-PEG-Cy5) was cubed with $\mathrm{CCm}_{231}$ for $30 \mathrm{~min}$ at $37{ }^{\circ} \mathrm{C}$ to obtain $\mathrm{Cy} 5$ DSPE-PEG-CCm ${ }_{231}$ and mixing them with UCNPs. The mixture was subsequently extruded 11 times through $400 \mathrm{~nm}$ polycarbonate membrane to get Cy5-DSPE-PEG-CCm $231^{-}$ UCNPs. Cells were incubated $4 \mathrm{~h}$ with Cy5-DSPE-PEG$\mathrm{CCm}_{231}$-UCNPs. To exclude the effect of DSPE-PEG-Cy5, MDA-MB-231 cells were incubated with DSPE-PEG-Cy5 for $4 \mathrm{~h}$. Cell nuclei were stained with 4',6-diamidino-2-phenylindole (DAPI), and confocal laser scanning microscopy (CLSM) under an external $650 \mathrm{~nm}$ laser was used to image.

A CCK-8 assay was used to evaluate the cytotoxicity of nanoparticles to MDA-MB-231 cancer cells. Cells were seeded in 96-well plates at a density of $3 \times 10^{3}$ cells per well and cultured for $12 \mathrm{~h}$. Then UCNPs and $\mathrm{CCm}_{231}$-UCNPs at various concentrations (i.e., 5, 25, 50, 100, and $500 \mu \mathrm{g} \mathrm{mL}^{-1}$ ) were added to the medium, and the cells were incubated for another $24 \mathrm{~h}$. The cells grown without any nanoparticles were used as a control. At the end of the incubation, $5 \mathrm{mg} \mathrm{mL}{ }^{-1}$ CCK-8 PBS solution was added, and the plate was incubated for another $4 \mathrm{~h}$. Finally, the absorbance values of the cells per well were determined with a microplate reader (Bio-Rad, Hercules, CA, USA) at $450 \mathrm{~nm}$ for analyzing the cell viability. The background absorbance of the well plate was measured and subtracted. The cytotoxicity was calculated by dividing the optical density (OD) values of treated groups $(T)$ by the OD values of the control $(C)$ $(T / C \times 100 \%)$.

\subsection{Animals and Tumor Model}

Animals received care under the instruction of the Guidance Suggestions for the Care and Use of Laboratory Animals. Four- to six-week-old female BALB/c nude mice (Beijing HuaFuKang Bioscience Co. Ltd, China) were subcutaneously injected with $100 \mu \mathrm{L}$ serum-free PBS containing $5 \times 10^{6}$ MDA-MB-231 cells or MCF-7 cells into the upper limbs or lower limbs of each mouse, according to the imaging situation. About 1 week after the injection, when the tumor volume reached $60-250 \mathrm{~mm}^{3}$, the tumor-bearing mice model would be used for further experiments.

\subsection{In Vivo Imaging}

When the volumes of MDA-MB-231 tumor or MCF-7 tumor reached $60-250 \mathrm{~mm}^{3}$, the BALB/c nude mice were divided into groups randomly and received an i.v. injection of $200 \mu \mathrm{L}$ PBS or PBS containing the different nanoparticle preparations (i.e., UCNPs, RBC-UCNPs, and $\mathrm{CCm}_{231^{-}}$UCNPs) at the concentration of $5 \mathrm{mg} \mathrm{mL}^{-1}$ via the tail vein. All mice were anesthetized by isoflurane. For in vivo UCL imaging, the fluorescence signals were obtained by an ex/in vivo imaging system (IVIS Lumina XRMS Series III, PerkinElmer Inc.) equipped with fluorescent filter sets (excitation/ emission $=980 / 790 \mathrm{~nm}$ ) at $0,3,6,12,24,36$, and $48 \mathrm{~h}$ after the injection. Then all mice were killed to obtain the tumor and major organs (heart, liver, spleen, lung, kidneys) to conduct the ex vivo UCL signals through the ex/in vivo imaging system (IVIS Lumina XRMS Series III, PerkinElmer Inc.).

For in vivo MR imaging, the dose level was set to $15 \mathrm{mg}$ of $\mathrm{Gd}$ per kilogram body weight for $\mathrm{CCm}_{231}$-UCNPs, RBCm-UCNPs, UCNPs, and Gd-DTPA. The MR images were acquired on a 7.0 T animal MRI instrument (BioSpec 70/20 USR, Bruker, Karlsruhe, Germany) after 24-h injection of $\mathrm{CCm}_{231}$-UCNPs, RBCm-UCNPs, and UCNPs. As 
for the Gd-DTPA group, images were acquired immediately after the injection of Gd-DTPA. The detailed imaging parameters were set as follows: echo time $(\mathrm{TE})=15.3 \mathrm{~ms}$; repetition time $(\mathrm{TR})=500,1000,1500,2000 \mathrm{~ms}$; number of excitations $(\mathrm{NEX})=8$ [8].

PET imaging was performed on a micro-PET (TransPET $^{\circledR}$ BioCaliburn ${ }^{\circledR}$ LH, Raycan Technology Co., Ltd., Suzhou, China). 1, 2-Distearoyl-sn-glycero-3-phosphoethanolamine-N-[azido (polyethylene glycol)-2000] (DSPE-PEG$\mathrm{N}_{3}$ ) was incubated with $\mathrm{CCm}_{231}$ for $30 \mathrm{~min}$ at $37^{\circ} \mathrm{C}$ to form $\mathrm{N}_{3}$-PEG-DSPE-CCm ${ }_{231}$-UCNPs. The tumor-bearing mice were first injected with $\mathrm{N}_{3}$-DSPE-PEG-CCm 231 -UCNPs, $\mathrm{N}_{3}$-DSPE-PEG-RBCm-UCNPs, or $\mathrm{N}_{3}$-DSPE-PEG, and then $24 \mathrm{~h}$ after the injection, $\mathrm{Al}\left[{ }^{18} \mathrm{~F}\right] \mathrm{F}-\mathrm{L}-\mathrm{NETA}-\mathrm{DBCO}$ was subsequently injected into the tumor-bearing mice via tail vein. First, L-NETA-DBCO was successfully radiolabeled with ${ }^{18} \mathrm{~F}$ via $\mathrm{Al}-{ }^{18} \mathrm{~F}$ chelation [33], and then, ${ }^{18} \mathrm{~F}$-labeled aza-dibenzocyclooctyne (DBCO) radioligands $\left(\mathrm{Al}\left[{ }^{18} \mathrm{~F}\right]\right.$ F-L-NETA-DBCO) were conjugated with azide-modified UCNPs by in vivo strain-promoted alkyne azide cycloaddition (SPAAC), which enables PET imaging [34]. PET static imaging was performed at $0.5,1,2$, and $4 \mathrm{~h}$ after the injection of $\mathrm{Al}\left[{ }^{18} \mathrm{~F}\right] \mathrm{F}-\mathrm{L}-\mathrm{NETA}-\mathrm{DBCO}$.

To measure the stability of the probe $\mathrm{Al}\left[{ }^{18} \mathrm{~F}\right] \mathrm{F}-\mathrm{L}-\mathrm{NETA}$ DBCO, quality control was performed by high-performance liquid chromatography (HPLC) at $0,0.5,1,2$, and $4 \mathrm{~h}$. In vivo stability testing was also conducted. After injection of the probe $\mathrm{Al}\left[{ }^{18} \mathrm{~F}\right] \mathrm{F}-\mathrm{L}-\mathrm{NETA}-\mathrm{DBCO}$ into $\mathrm{BALB} / \mathrm{c}$ nude mice, the blood was obtained at $2 \mathrm{~h}$ and $4 \mathrm{~h}$ after the injection and analyzed with HPLC.

\subsection{Biodistribution Studies}

MDA-MB-231 or MCF-7 tumor-bearing mice injected with $\mathrm{N}_{3}$-DSPE-PEG-CCm 231 -UCNPs and $\mathrm{Al}\left[{ }^{18} \mathrm{~F}\right] \mathrm{F}-\mathrm{L}-\mathrm{NETA}$ $\mathrm{DBCO}$ to evaluate whole-body elimination and excretion were killed by cervical dislocation under anesthesia using isoflurane; samples of blood, normal tissues (including brain, heart, lung, liver, spleen, kidney, stomach, small intestine, large intestine, muscle, bone), and tumor were collected and weighed; and the radioactivity in each was measured in a $\gamma$-counter. Tissue radioactivity was calculated as percent injected dose/g (\% ID/g) and then converted to \% ID/organ using previously determined standard organ weights. The concentration of $\mathrm{Gd}^{3+}$ in each organ was then measured by inductively coupled plasma-atomic emission spectroscopy (ICP-AES). For this analysis, samples were prepared as described by Rao et al. [16]. ICP-AES was performed using a Prodigy 7 (Leeman Labs Inc., Hudson, NH, USA) instrument, and the concentration $\left(\mathrm{mg} \mathrm{L}^{-1}\right)$ of $\mathrm{Gd}^{3+}$ in the tissues was obtained by reference to a standard curve.

\subsection{Biotoxicity Evaluation}

For evaluating systematic toxicity, BALB/c nude mice $(n=6)$ received an injection of $200 \mu \mathrm{L}$ of PBS, or PBS containing UCNPs or $\mathrm{CCm}_{231}$-UCNPs at a concentration of $5 \mathrm{mg} \mathrm{mL}^{-1}$, or PBS containing equivalent numbers of $\mathrm{CCm}_{231^{-}}$-vesicles. Death and body weight were observed for 30 days. On the 30th day after the injection, all the mice were euthanized and their blood and major organs were collected for blood biochemistry (red blood cells (RBCs), white blood cells (WBCs), platelets (PLT), hemoglobin (HGB), hematocrit (HCT), mean corpuscular volume (MCV), mean corpuscular hemoglobin $(\mathrm{MCH})$ and mean corpuscular hemoglobin concentration (MCHC)), hematology tests (alkaline phosphatase (ALP), aspartate aminotransferase (AST), alanine transaminase (ALT), creatinine (CRE) and blood urea nitrogen (BUN)), and histology analysis (hematoxylin and eosin (H\&E)-stained slices).

\subsection{Statistical Analysis}

Results are expressed as mean \pm standard error of the mean. Data analyses were conducted using the software GraphPad Prism 6.0 (GraphPad Software, San Diego, CA, USA). The differences among groups were analyzed using one-way ANOVA followed by Tukey's post-test. $P$ value of $<0.05$ indicates statistical significance.

\section{Results and Discussion}

\subsection{Preparation and Characterization of $\mathrm{CCm}-\mathrm{UCNPs}$}

To construct CCm-UCNPs, MDA-MB-231 cells, as the membrane source, were processed by using the method reported by Rao et al. [16]. Briefly, the membrane derivation was achieved through a combination of hypotonic lysis, mechanical membrane disruption, and differential centrifugation. With the collected membranes, $\mathrm{CCm}$ vesicles were then formed by physical extrusion through 
a 400-nm porous polycarbonate membrane on a mini extruder. Then, mixing UCNPs with the membranes by ultrasound and repeating the physical extrusion through a 200-nm pore, CCm was then coated by physical extrusion to form $\mathrm{CCm}_{231}$-UCNPs. As measured by dynamic light scattering (DLS), the hydrodynamic size of the UCNPs was approximate $75 \mathrm{~nm}$ (Fig. 1a, b), while that of $\mathrm{CCm}_{231}$ was around $400 \mathrm{~nm}$. Upon optimization of UCNPs: $\mathrm{CCm}_{231}$ ratio, $\mathrm{CCm}_{231}$-UCNPs of approximately $200 \mathrm{~nm}$ were obtained, which presented the best hydrodynamic size and polydispersity in comparison with those obtained with different UCNPs: $\mathrm{CCm}_{231}$ ratios (Fig. S1a). The zeta-potential measurements shown in Fig. 1c exhibited that the surface potential of $\mathrm{CCm}_{231}$-UCNPs was much closer to $\mathrm{CCm}_{231}$ rather than that of the mother UCNPs, indicating that $\mathrm{CCm}_{231}$ coating was successfully achieved. Transmission electron microscopy (TEM) is shown in Fig. 1d-g, the membrane coating around the UCNPs can be visualized with a thickness of around $3 \mathrm{~nm}$, and the $\mathrm{CCm}_{231}$ evenly was coated around the UNCP cores of $\sim 25 \mathrm{~nm}$. The as-prepared $\mathrm{CCm}_{231}$-UCNPs presented good colloidal stability in $1 \times$ phosphate-buffered saline $(\mathrm{PBS})$ for 3 days (Fig. S1b). Also, the upconversion luminescence $\mathrm{CCm}_{231}$-UCNPs remained nearly unaltered in comparison with that of UCNPs under excitation at $980 \mathrm{~nm}$ (Fig. S1c), (a)
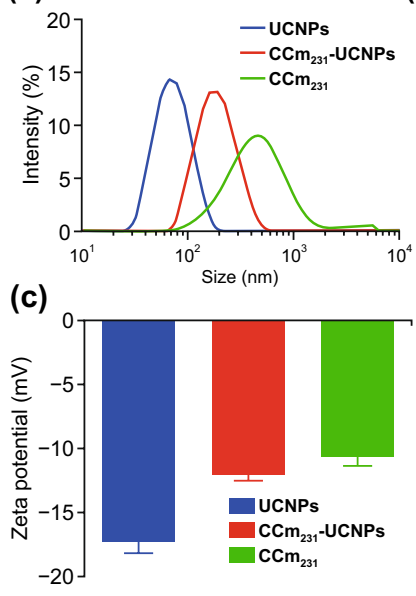

(c)

(b)
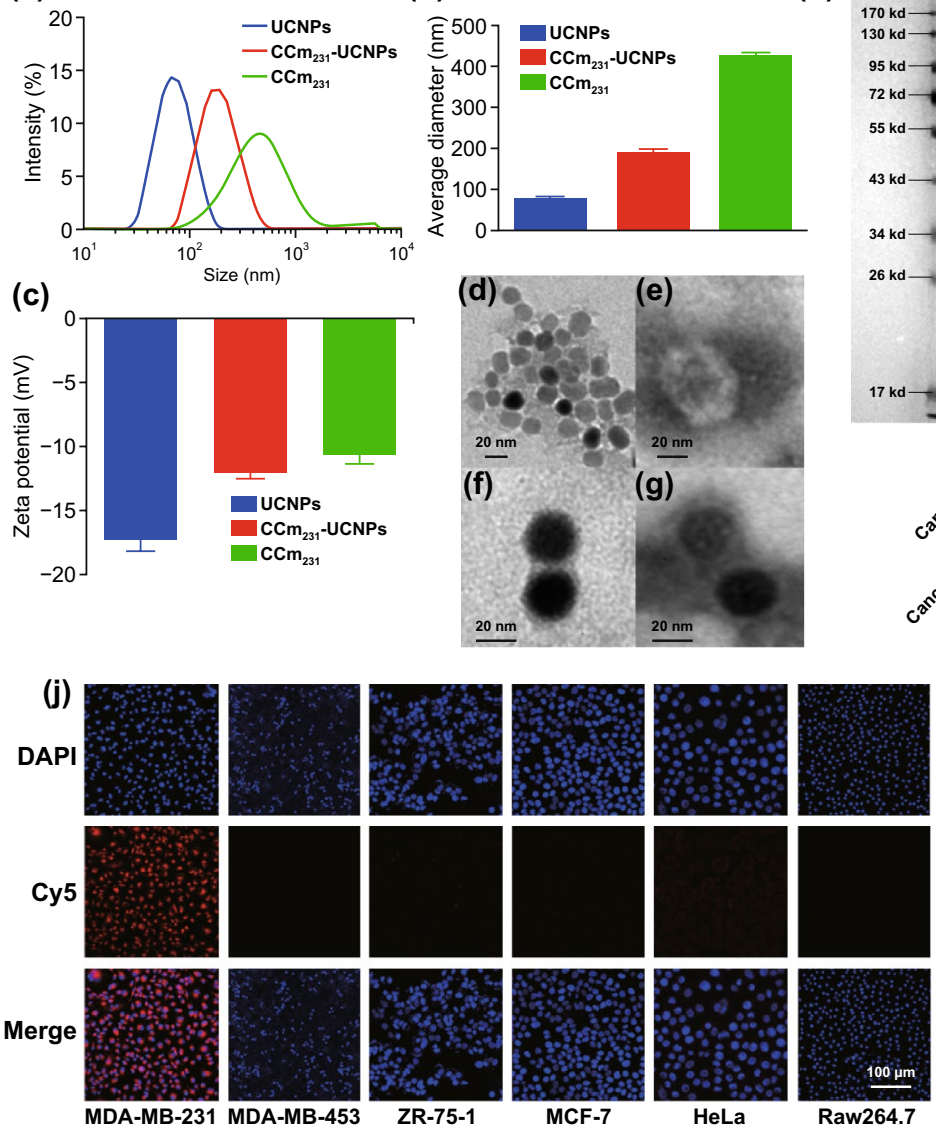

MCF-7 (i)
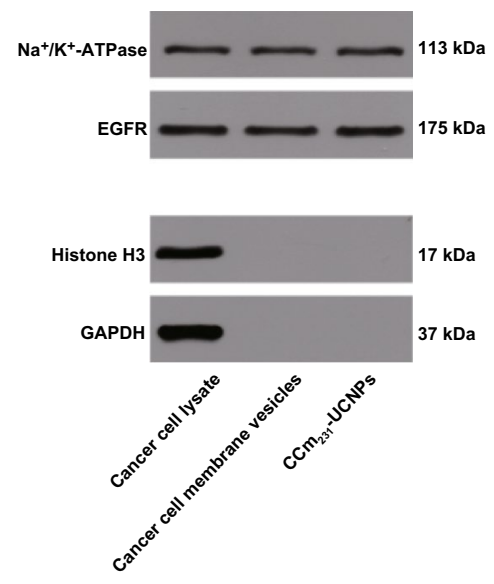
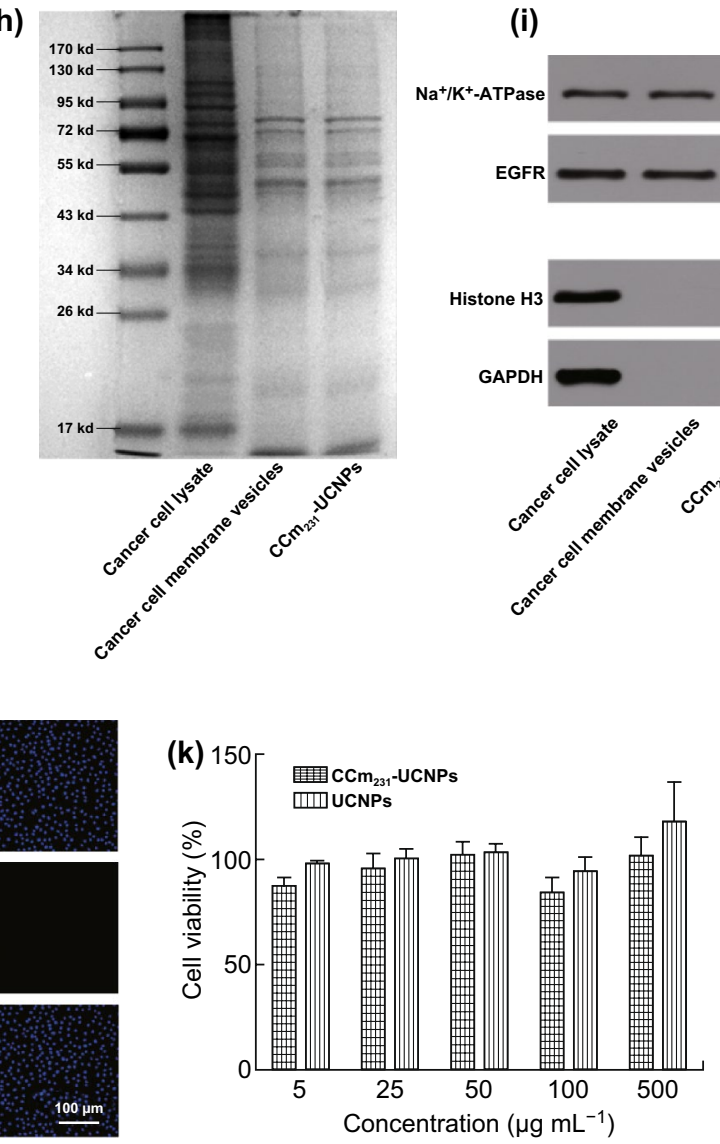

Fig. 1 Physicochemical characterization of $\mathrm{CCm}_{231}$-UCNPs. a Size intensity curves, b hydrodynamic size, and $\mathbf{c}$ zeta potential of UCNPs, $\mathrm{CCm}_{231}$-UCNPs, and $\mathrm{CCm}_{231}$ measured by dynamic light scattering (DLS). TEM images of $\mathbf{d} \mathrm{UCNPs}, \mathbf{e} \mathrm{CCm}_{231}$, and $\mathbf{f}, \mathbf{g} \mathrm{CCm}_{231}$-UCNPs. The TEM samples were negatively stained with phosphotungstic acid. The scale bars $=20 \mathrm{~nm}$. h SDS-PAGE protein analysis of MDA-MB-231 cancer cell lysate, cancer cell membrane vesicles, and $\mathrm{CCm}_{231}$-UCNPs. Samples were run at equal protein concentration and stained with Coomassie Blue. i Western blotting analysis. Samples were run at equal protein concentration and immunostained against membrane markers including $\mathrm{Na}^{+} / \mathrm{K}^{+}$-ATPase, EGFR, histone H3 (a nuclear marker), and glyceraldehyde 3-phosphate dehydrogenase (a cytosolic marker). In vitro homologous-targeting ability and cytotoxicity of $\mathrm{CCm}_{231}$-UCNPs. $\mathbf{j}$ Confocal laser scanning microscopy (CLSM) images of various cells after incubation with $\mathrm{CCm}_{231}$-UCNPs. The scale bars $=100 \mu \mathrm{m}$. $\mathbf{k}$ Survival of MDA-MB-231 cells treated with different concentrations of CCm 231 -UCNPs and UCNPs. The data points represent mean $\pm \mathrm{SD}(n=3)$ 
indicating that $\mathrm{CCm}$ coating did not affect the upconversion luminescence of UCNPs.

To confirm the existence of the $\mathrm{CCm}$ proteins on the UCNPs, the $\mathrm{CCm}_{231}$-UCNPs were subjected to sodium dodecyl sulfate-polyacrylamide gel electrophoresis (SDS-PAGE) and western blotting analysis. The SDS-PAGE results shown in Fig. $1 \mathrm{~h}$ revealed that $\mathrm{CCm}_{231}$-UCNPs presented a protein profile very similar to those of $\mathrm{CCm}_{231}$ and MDA-MB-231 cell lysate. The western blotting analysis confirmed that the $\mathrm{CCm}_{231}$-UCNPs well inherited the membrane-specific markers such as $\mathrm{Na}^{+} / \mathrm{K}^{+}$-ATPase and positive antigen EGFR from the MDA-MB-231 cells, while the control nuclear protein marker (i.e., histone H3) and the cytosol marker (i.e., glyceraldehyde 3-phosphate dehydrogenase (GAPDH)) were almost undetectable from the final $\mathrm{CCm}_{231}$-UCNPs, as shown in Fig. 1i.

\subsection{In Vitro Homologous Targeting and Cytotoxicity of $\mathrm{CCm}_{231}$-UCNPs}

It was expected that $\mathrm{CCm}_{231}$ coating would endow the $\mathrm{CCm}_{231}$-UCNPs with homologous-targeting ability. To evaluate such ability of $\mathrm{CCm}_{231}$-UCNPs in targeting MDAMB-231 cells, 1, 2-distearoyl-sn-glycero-3-phosphoethanolamine-N-(polyethylene glycol) 2000-Cy5 (DSPE-PEGCy5), a kind of cyanine dye, was inserted into $\mathrm{CCm}_{231}$ lipid bilayer to achieve Cy5-labeled $\mathrm{CCm}_{231}$-UCNPs [32], denoted as Cy5-DSPE-PEG-CCm 231 -UCNPs. Then, different types of tumor cells including human breast cancer cells MDA-MB-231, MCF-7, ZR-75-1, MDA-MB-453 (the phenotypes of various cells are shown in Table S1), and human cervical cancer cells (HeLa) were adopted to show the binding affinity of Cy5-DSPE-PEG-CCm 231 -UCNPs after co-incubated with the corresponding cells. The confocal laser scanning microscopy (CLSM) results given in Fig. $1 \mathrm{j}$ revealed that only MDA-MB-231 cells presented the strongest fluorescence after incubation with $\mathrm{Cy} 5$ DSPE-PEG-CCm ${ }_{231}$-UCNPs. These confirmed the specific homologous-targeting ability of $\mathrm{CCm}_{231}$-UCNPs to MDAMB-231 cells. There is some evidence proving that cancer cell membranes play an important role in immune tolerance in the tumor microenvironment [29]. To investigate the low immunogenicity of $\mathrm{CCm}_{231}$-UCNPs, murine macrophagelike cells (Raw264.7) were used. The Raw264.7 cells had nearly no uptake of Cy5-DSPE-PEG-CCm 231 -UCNPs
(Fig. 1j), indicating that CCm-UCNPs can obscure their identification by the mononuclear phagocyte system and indeed decreased immunogenicity. And MDA-MB-231 cells showed no uptake of DSPE-PEG-Cy5, which could exclude the effect of DSPE-PEG-Cy5 (Fig. S2).

The cholecystokinin (CCK)-8 assay was used to evaluate the cytotoxicity of UCNPs and $\mathrm{CCm}_{231}$-UCNPs to MDAMB-231 cells. MDA-MB-231 cells were co-incubated with UCNPs and $\mathrm{CCm}_{231}$-UCNPs at concentrations up to $500 \mu \mathrm{g} \mathrm{mL}^{-1}$ for $24 \mathrm{~h}$. The results revealed that the survival rates of cells in the UCNPs group and the $\mathrm{CCm}_{231}$-UCNPs group were both $>80 \%$ (Fig. 1k), indicating UCNPs and $\mathrm{CCm}_{231}$-UCNPs exerted no obvious toxicity toward MDAMB-231 cells.

\subsection{In Vivo UCL/MRI/PET Imaging}

In this work, we speculated that $\mathrm{CCm}_{231}$-UCNPs would exhibit the homologous-targeting ability to MDA-MB-231 cancer cells in vivo. We set red blood cell membrane-coated UCNPs (RBCm-UCNPs) in PBS as a control to compare the results of homologous targeting and passive targeting. PBS or PBS containing $\mathrm{CCm}_{231}$-UCNPs, RBCm-UCNPs, or UCNPs at the same concentration were injected into MDAMB-231 subcutaneous-tumor-bearing BALB/c nude mice through the tail vein. To avoid the impact of liver uptake on tumor area imaging, we injected cancer cells into the lower limb of the mice models [12, 15, 16, 29].

For in vivo UCL imaging, the fluorescence signals were obtained after the injection. As shown in Fig. 2a, the $\mathrm{CCm}_{231}$-UCNPs group displayed the strongest UCL signal in the tumor site, demonstrating the homologous binding ability of $\mathrm{CCm}_{231}$-UCNPs to target MDA-MB-231 tumors. The RBCm-UCNPs group showed similar tumor accumulation to the UCNPs group attributed to the EPR effect, but lower fluorescence signal compared to that of the $\mathrm{CCm}_{231}$-UCNPs group. Liver is one of the primary organs of the phagocyteenriched reticuloendothelial system (RES) [30] and can accumulate the most nanoparticles [31]. Liver accumulation by the $\mathrm{CCm}_{231}$-UCNPs group was much lower than that of the UCNPs group, indicating that $\mathrm{CCm}$ coating can indeed decrease the RES uptake. In the $\mathrm{CCm}_{231}$-UCNPs group, the liver signal was of short duration, almost disappeared in $24 \mathrm{~h}$, while the tumor signal lasted much longer, up to $48 \mathrm{~h}$. The best imaging time was at $24 \mathrm{~h}$ after the injection 


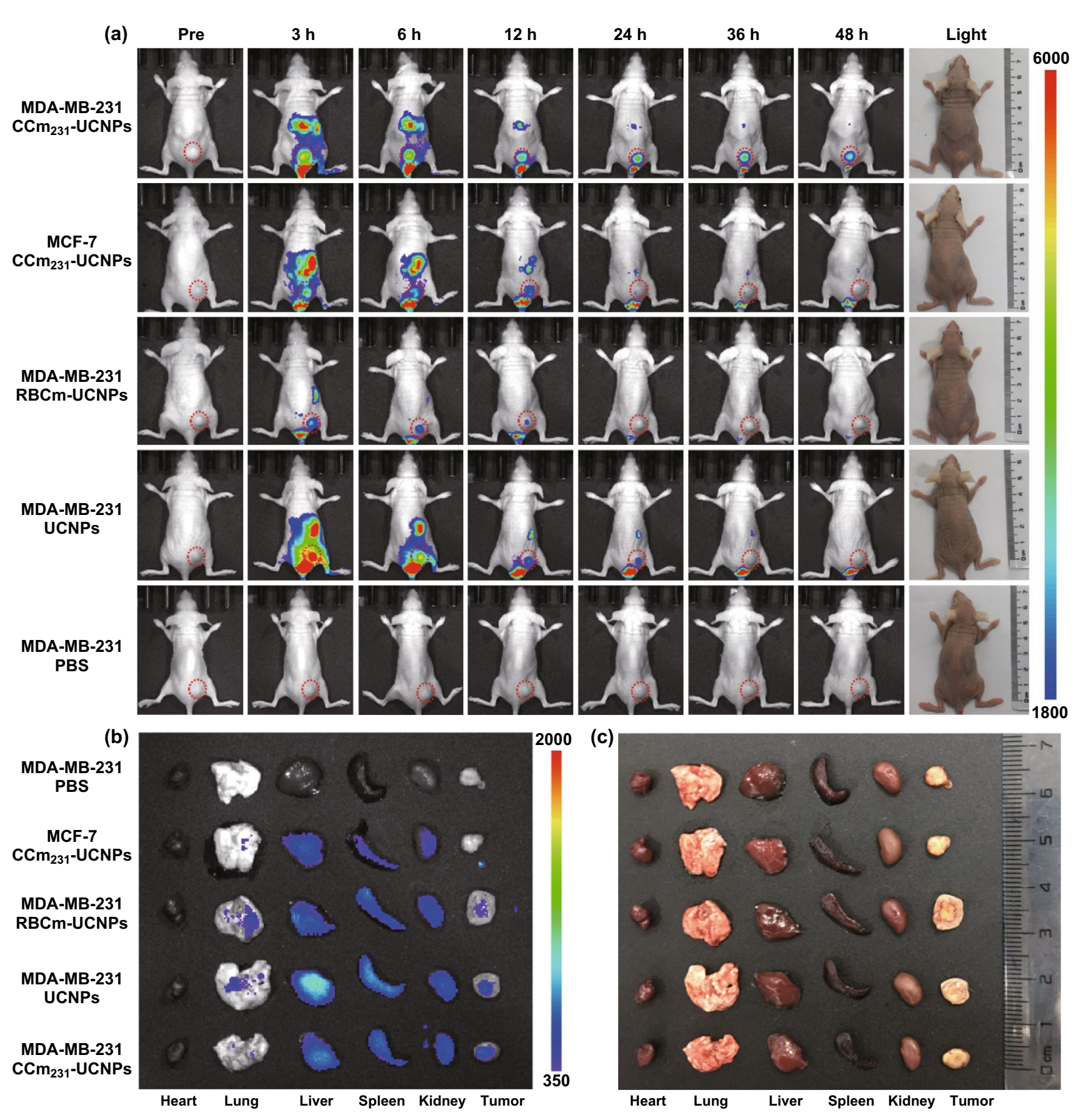

Fig. 2 Homologous-targeting evaluation and in vivo upconversion luminescence (UCL) imaging. a BALB/c nude tumor-bearing mice injected with PBS or PBS containing UCNPs, RBCm-UCNPs, and $\mathrm{CCm}_{231}$-UCNPs at different times after the injection. b, $\mathbf{c}$ Ex vivo UCL images of tumors and major organs of the killed mice at $48 \mathrm{~h}$ after the injection

with high uptake by the tumor and low uptake by the liver, indicating the feasibility of using the $\mathrm{CCm}_{231}$-UCNPs for imaging and treatment delivery. To investigate the homologous-targeting ability, $\mathrm{CCm}_{231}$-UCNPs were injected into MDA-MB-231 and MCF-7 tumor-bearing mice. The UCL signal in the MDA-MB-231 group was much higher than that of the MCF-7 group (Fig. 2a), further showing the enhanced specificity accomplished by CCm coating. At $48 \mathrm{~h}$ after injection, all the mice were killed and the tumors and other major organs were collected for ex vivo UCL imaging. 
As shown in Fig. 2b, c, $\mathrm{CCm}_{231}$-UCNPs injected into MDAMB-231 tumor-bearing mice displayed the highest rate of tumor accumulation. The amount of $\mathrm{CCm}_{231}$-UCNPs accumulated in the liver and spleen was much lower than that of UCNPs.

For in vivo MR imaging, the groups were set the same as those for UCL imaging. T1-weighted MR images were obtained at $24 \mathrm{~h}$ after the injection. The images of the GdDTPA group were acquired immediately after the injection. The group injected with $\mathrm{CCm}_{231}$-UCNPs showed slight enhancement in the tumor region compared to the groups injected with RBCm-UCNPs and UCNPs (Fig. 3a). Similarly, the tumor regions of $\mathrm{CCm}_{231}$-UCNPs injected into the MDA-MB-231 tumor groups were slightly enhancing than the $\mathrm{CCm}_{231}$-UCNPs injected into the MCF-7 groups (Fig. 3a).

For PET imaging, we used pre-targeting technology and click chemistry (Scheme S1). 1, 2-Distearoylsn-glycero-3-phosphoethanolamine-N-[azido (polyethylene glycol)-2000] (DSPE-PEG-N 3 ) was inserted into $\mathrm{CCm}_{231}$ to obtain $\mathrm{N}_{3}$-PEG-DSPE-CCm 231 -UCNPs [32]. According to the UCL imaging, we chose to inject $\mathrm{N}_{3}$-DSPE-PEG-CCm ${ }_{231}$-UCNPs $24 \mathrm{~h}$ before the injection of ${ }^{18} \mathrm{~F}$-labeled radioligands $\mathrm{Al}\left[{ }^{18} \mathrm{~F}\right] \mathrm{F}-\mathrm{L}-\mathrm{NETA}-\mathrm{DBCO}$ [33, 34]. The radioactive stability results are shown in Fig. S3. The cancer cells were injected into the upper limb of the mice to avoid the interference of the intestine and bladder on the imaging of the tumor area. Micro-PET static (a)

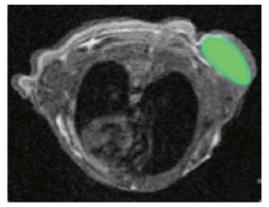

MDA-MB-231

CCm 231 -UCNPs

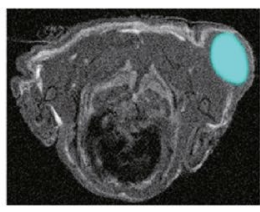

MCF-7

$\mathrm{CCm}_{231}$-UCNPs

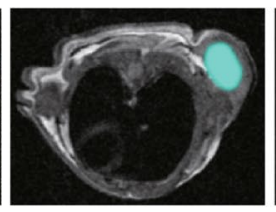

MDA-MB-231

RBCm-UCNPs

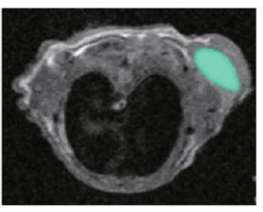

MDA-MB-231

UCNPs

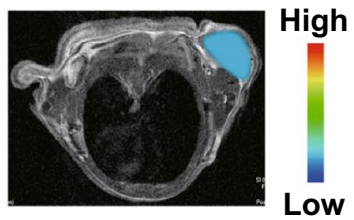

MDA-MB-231

Gd-DTPA
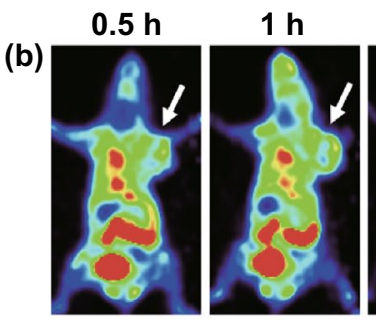

$2 \mathrm{~h}$

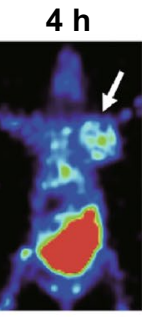

MDA-MB-231

$\mathrm{N}_{3}$-DSPE-PEG-CCm 231 -UCNPs

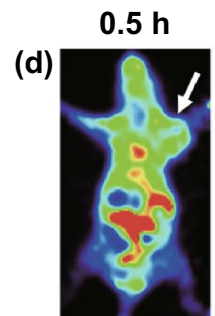

$1 \mathrm{~h}$
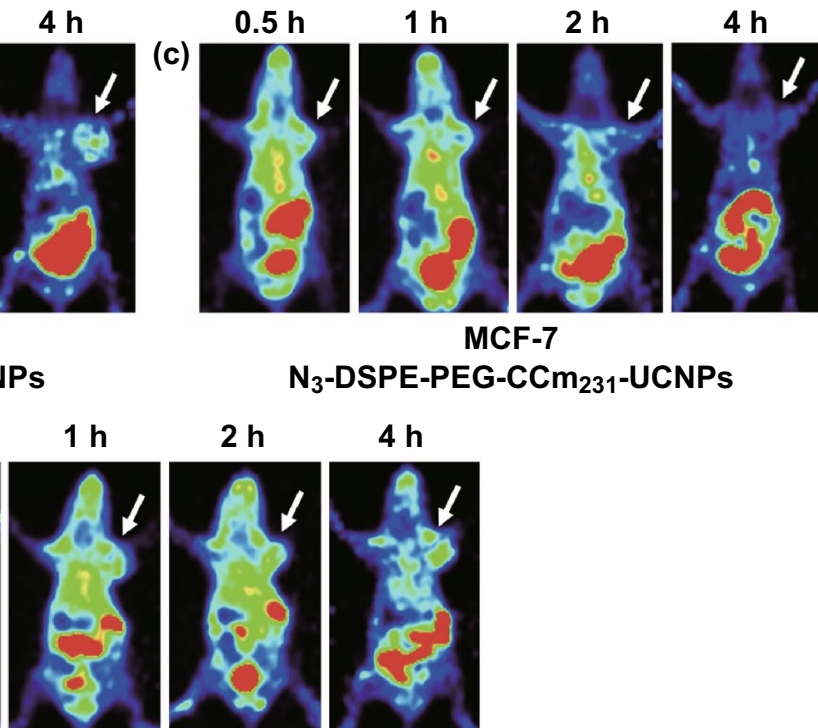

$7 \% \mathrm{ID} / \mathrm{g}$

$\mathrm{N}_{3}$-DSPE-PEG-CCm 231 -UCNPs

$2 \mathbf{h}$

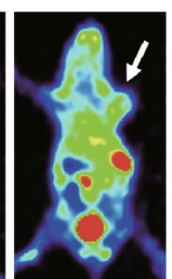

$4 \mathrm{~h}$

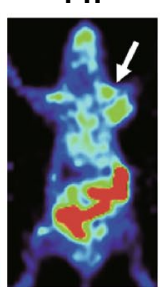

MDA-MB-231

$\mathrm{N}_{3}$-DSPE-PEG-RBCm-UCNPs

Fig. 3 In vivo MR imaging. T1-weighted MR images acquired at $24 \mathrm{~h}$ after the injection of nanoparticles. a BALB/c nude tumor-bearing mice injected with Gd-DTPA or PBS containing $\mathrm{CCm}_{231}$-UCNPs, RBCm-UCNPs, UCNPs. The tumor sites are color-coded to better show the contrast-enhancing effects. In vivo PET imaging. Micro-PET static imaging was performed at $0.5,1,2$, and $4 \mathrm{~h}$ after injection of $\mathrm{Al}\left[{ }^{18} \mathrm{~F}\right] \mathrm{F}-\mathrm{L}-$ NETA-DBCO. b MDA-MB-231 tumor-bearing mice injected with $\mathrm{N}_{3}$-DSPE-PEG-CCm ${ }_{231}$-UCNPs. $\mathbf{c}$ MCF-7 tumor-bearing mice injected with $\mathrm{N}_{3}$-DSPE-PEG-CCm 231 -UCNPs. d MDA-MB-231 tumor-bearing mice injected with $\mathrm{N}_{3}$-DSPE-PEG-RBCm-UCNPs 
imaging was performed at $0.5,1,2$, and $4 \mathrm{~h}$ after injection of $\mathrm{Al}\left[{ }^{18} \mathrm{~F}\right] \mathrm{F}-\mathrm{L}-\mathrm{NETA}-\mathrm{DBCO}$. Images indicated that the $\mathrm{N}_{3}$-DSPE-PEG-CCm ${ }_{231}$-UCNPs group showed the highest uptake on tumor site at various times compared with other groups (Figs. 3b-d and S4). Also, the liver and spleen uptake were low. Injecting $\mathrm{N}_{3}$-DSPE-PEG-CCm 231 -UCNPs into MDA-MB-231 and MCF-7 tumor-bearing mice, respectively, the tumor site uptake of the MDA-MB-231 group was much higher than that of the MCF-7 group (Fig. 3b, c). The results were in accordance with that of UCL and MR imaging. Considering all these multimodality imaging results, we demonstrated that $\mathrm{CCm}_{231}$-UCNPs targeted to MDA-MB-231 tumors and were of greatly reduced immunogenicity.

\subsection{Biodistribution of $\mathrm{CCm}_{231}$-UCNPs}

To quantitatively analyze the biodistribution of the probe, all the mice were killed, and blood samples, tumors, and major organs were collected for biological distribution by an automatic gamma counter. We injected $\mathrm{N}_{3}$-DSPE-PEG-CCm ${ }_{231}$-UCNPs $24 \mathrm{~h}$ in advance, and the biodistribution was performed at $0.5,1,2$, and $4 \mathrm{~h}$ after the injection of $\mathrm{Al}\left[{ }^{18} \mathrm{~F}\right] \mathrm{F}-\mathrm{L}-\mathrm{NETA}-\mathrm{DBCO}$. Comparing tumor uptake of ${ }^{18} \mathrm{~F}$ by the $\mathrm{CCm}_{231}$-UCNPs to MCF-7 model group (Table S2), $\mathrm{CCm}_{231}$-UCNPs to MDA-MB-231 model group (Table S3) showed significantly higher accumulation in the tumor $(P<0.001)$ (Fig. 4a, b); the results were in accord with that of imaging. Furthermore, the much higher tumorto-blood ratios (T/B) and tumor-to-muscle ratios (T/M) of MDA-MB-231 model group were seen than those of MCF-7 model group $(P<0.05)$ (Table S2). It proved that $\mathrm{CCm}$-coated nanoparticles had homologous-targeting ability. It could be inferred that the homologous-targeting ability of CCm-UCNPs can be widely applied to other types of tumors.

The detection of the ${ }^{18} \mathrm{~F}$ signal can only indirectly determine the biodistribution of nanoparticles, while directly detecting the distribution of $\mathrm{Gd}^{3+}$ in various tissues in the body must be achieved by inductively coupled plasma-atomic emission spectroscopy (ICPAES). The results showed that the biodistribution of $\mathrm{CCm}_{231}$-UCNPs was mainly concentrated in the liver and spleen, and was rarely distributed in blood, heart, and lung (Fig. 4c and Table S4). The $\mathrm{Gd}^{3+}$ uptake in the liver measured by ICP-AES for UCNPs was 1.82 -fold
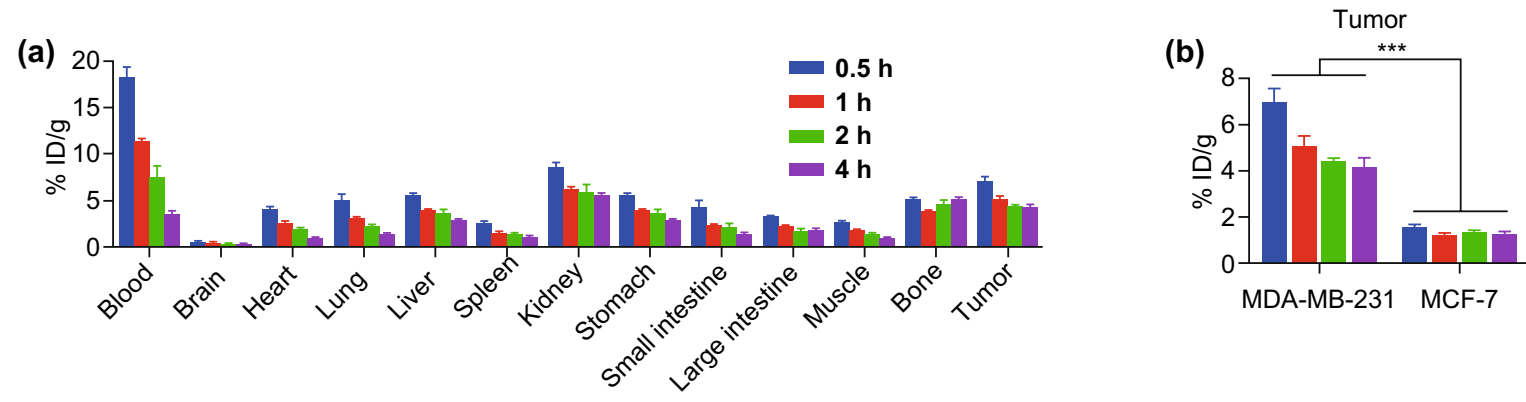

(c)

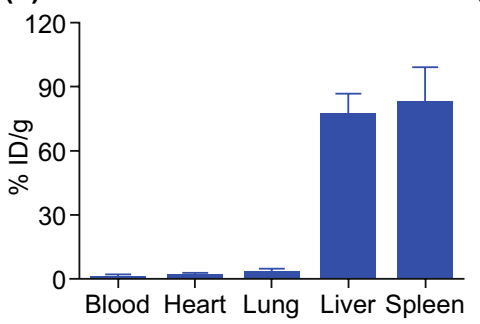

(d)

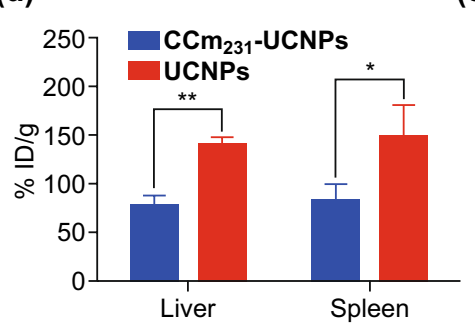

(e)

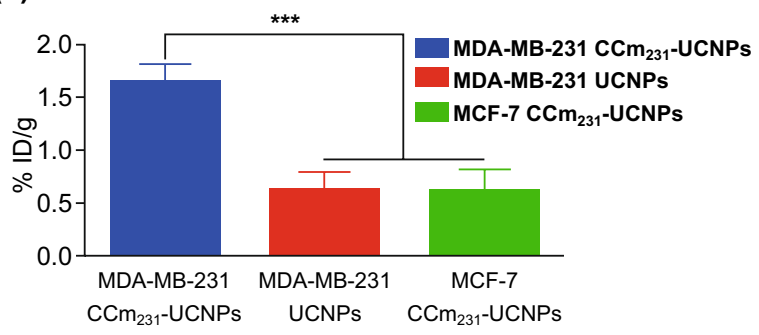

Fig. 4 a Biodistribution of ${ }^{18} \mathrm{~F}$ in different organs and tumors in MDA-MB-231 tumor-bearing mice at different times after the injection. b Tumor uptake of ${ }^{18} \mathrm{~F}$ comparing in MDA-MB-231 and MCF-7 tumor-bearing mice. Biodistribution of $\mathrm{Gd}^{3+}$ in different organs, tissues, and tumors. $\mathbf{c} \mathrm{CCm}_{231}$-UCNPs in the blood, heart, lung, liver, and spleen. $\mathbf{d ~ C C m}_{231}$-UCNPs and UCNPs in the liver and spleen. e Tumor uptake of $\mathrm{Gd}^{3+}$ in the MDA-MB-231 $\mathrm{CCm}_{231}$-UCNPs group, the MDA-MB-231 UCNPs group, and the MCF-7 CCm 231 -UCNPs group. *, **, and *** indicate $P<0.05, P<0.01$, and $P<0.001$, respectively. Data points represent mean $\pm \mathrm{SD}(n=4)$ 
(a)
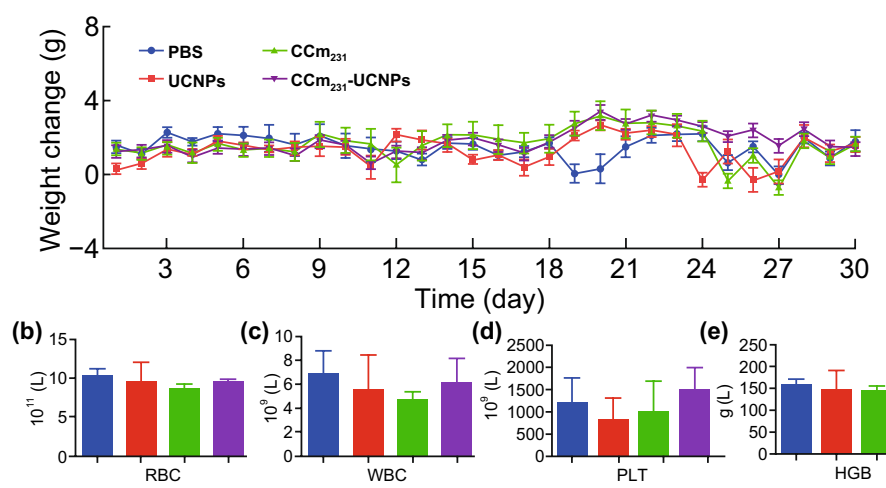

(c) 10

(d) 2500

(e) 250
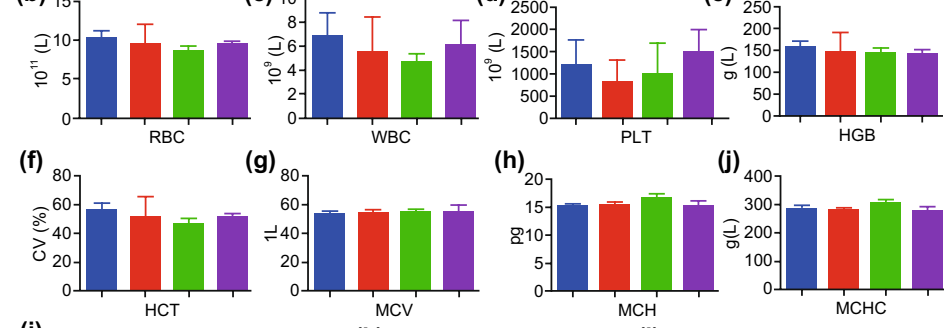

(h)

(j) 400

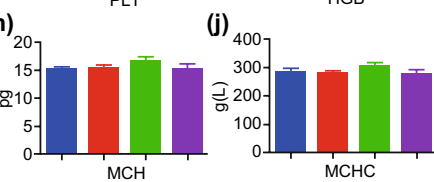

(m)

PBS
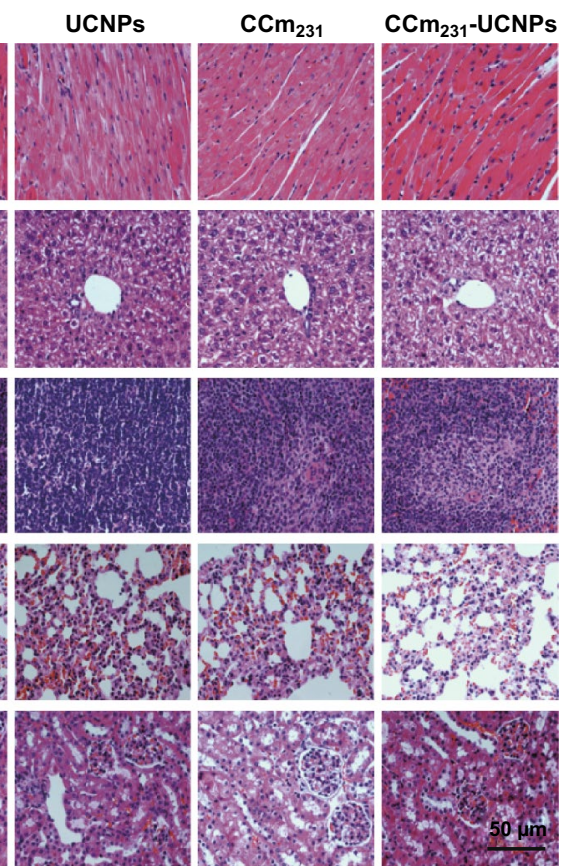

Fig. 5 In vivo toxicity evaluation. a Mice body-weight-change curves over 30 days after i.v. injection with PBS or PBS containing UCNPs, $\mathrm{CCm}_{231}$, and $\mathrm{CCm}_{231}$-UCNPs. b-i Blood parameter data. Red blood cells (RBCs), white blood cells (WBCs), platelets (PLT), hemoglobin (HGB), hematocrit (HCT), mean corpuscular volume (MCV), mean corpuscular hemoglobin (MCH), and mean corpuscular hemoglobin concentration (MCHC). $\mathbf{j}-\mathbf{l}$ Blood biochemistry data. Alkaline phosphatase (ALP), aspartate aminotransferase (AST), alanine transaminase (ALT), creatinine $(\mathrm{CRE})$, and blood urea nitrogen $(\mathrm{BUN})$. $\mathbf{m}$ H\&E-stained slice images of major organs. The scale bars $=50 \mu \mathrm{m}$. The data points represent the mean $\pm \operatorname{SD}(n=6)$

higher than $\mathrm{CCm}_{231}$-UCNPs $(P<0.001)$, and splenic uptake of $\mathrm{Gd}^{3+}$ for UCNPs was 1.79 -fold greater than for $\mathrm{CCm}_{231}$-UCNPs $(P<0.05)$ (Fig. $\left.4 \mathrm{~d}\right)$. These results indicated that the uptake of $\mathrm{CCm}_{231}$-UCNPs by the liver and spleen was greatly reduced after coating with $\mathrm{CCm}$, which proved their lowered immunogenicity. Tumor uptake of $\mathrm{Gd}^{3+}$ for $\mathrm{CCm}_{231}$-UCNPs was 2.62-fold higher than UCNPs $(P<0.001)$ (Fig. 4 e). Also, the $\mathrm{Gd}^{3+}$ uptake in the tumor for $\mathrm{CCm}_{231}$-UCNPs to the MDA-MB-231 model group was 2.70-fold higher than that in $\mathrm{CCm}_{231}$-UCNPs to MCF-7 model group $(P<0.001)$ (Fig. 4e). There were significant differences in tumor uptake of $\mathrm{Gd}^{3+}$, showing that $\mathrm{CCm}_{231}$-UCNPs can homologously target tumors. The minimal uptake of UCNPs in the tumors may be attributed to the EPR effect. The difference between the MDA-MB-231 and MCF-7 model groups proved that $\mathrm{CCm}_{231}$-UCNPs could be used for the molecular classification of breast cancer in the future.

\subsection{In Vivo Toxicity Evaluation}

There is always a concern about potential toxicity and whether cancer cells or their membranes confer a cancer risk. For evaluating systematic toxicity, BALB/c nude mice received an injection of PBS, or PBS containing UCNPs, $\mathrm{CCm}_{231}$-vesicles, or $\mathrm{CCm}_{231}$-UCNPs. Neither death nor significant differences in body weight among the four groups were observed after 30 days (Fig. 5a). On the 30th day after the injection, all the mice were euthanized and their blood and major organs were collected for blood biochemistry, hematology tests, and histology analysis. We observed no significant differences between the treatment groups and control groups in the blood parameters and blood biochemistry indicators (Fig. 5b-1), and no significant organ damage on hematoxylin and eosin (H\&E)-stained slices (Fig. 5m). Above all, the results suggested no obvious toxicity or carcinogenicity of $\mathrm{CCm}_{231}$-UCNPs in vivo. 


\section{Conclusion}

In conclusion, we designed a novel probe using MDAMB-231 cancer cell membrane-mimic $\mathrm{Gd}^{3+}$-doped upconversion nanoparticles (CCm-UCNPs). In this probe, natural cell membranes isolated from cancer cells were coated into the UCNPs. The probe exhibited homologoustargeting and immune escaping abilities. Together with the upconversion luminescence of UCNPs, the paramagnetism of $\mathrm{Gd}^{3+}$, and click chemistry with surface modification to label ${ }^{18} \mathrm{~F}, \mathrm{CCm}$-UCNPs were used for ultra-sensitive in vivo $\mathrm{UCL} / \mathrm{MRI} / \mathrm{PET}$ multimodality precise imaging of TNBC, and differentiating MDA-MB-231 and MCF-7 tumor-bearing mice models in vivo.

Based on these results, this probe can also be modified for drug delivery, contributing to the treatment of TNBC. It may also be a potential method to achieve integration of diagnosis and treatment [35], as well as to monitor and evaluate therapeutic effects. In addition, apart from cancer cell membranes, various membrane functions, including chemotaxis of platelets to atherosclerotic plaque [25-27, 36], chemotaxis of leukocytes to inflammation [37], phagocytosis of macrophages [38], and cancer-targeting capabilities of stem cells [39], have the potential to be used for targeting different lesions. We believe this field has promising application prospects.

Acknowledgements Hanyi Fang, Mengting Li, and Qingyao Liu contributed equally to this work. This work was supported by the National Natural Science Foundation of China (Nos. 81630049 and 81501532).

Open Access This article is licensed under a Creative Commons Attribution 4.0 International License, which permits use, sharing, adaptation, distribution and reproduction in any medium or format, as long as you give appropriate credit to the original author(s) and the source, provide a link to the Creative Commons licence, and indicate if changes were made. The images or other third party material in this article are included in the article's Creative Commons licence, unless indicated otherwise in a credit line to the material. If material is not included in the article's Creative Commons licence and your intended use is not permitted by statutory regulation or exceeds the permitted use, you will need to obtain permission directly from the copyright holder. To view a copy of this licence, visit http://creativecommons.org/licenses/by/4.0/.

Electronic supplementary material The online version of this article (https://doi.org/10.1007/s40820-020-0396-4) contains supplementary material, which is available to authorized users.

\section{References}

1. F. Bray, J. Ferlay, I. Soerjomataram, R.L. Siegel, L.A. Torre, A. Jemal, Global cancer statistics 2018: GLOBOCAN estimates of incidence and mortality worldwide for 36 cancers in 185 countries. CA Cancer J. Clin. 68(6), 394-424 (2018). https://doi.org/10.3322/caac.21492

2. J.Y.S. Tsang, G.M. Tse, Molecular classification of breast cancer. Adv. Anat. Pathol. 27(1), 27-35 (2020). https://doi. org/10.1097/PAP.0000000000000232

3. J.H. Park, J.H. Ahn, S.B. Kim, How shall we treat early triplenegative breast cancer (TNBC): from the current standard to upcoming immuno-molecular strategies. ESMO Open 3(Suppl 1), e000357 (2018). https://doi.org/10.1136/esmoopen-2018000357

4. A.V. Chudgar, D.A. Mankoff, Molecular imaging and precision medicine in breast cancer. PET Clin. 12(1), 39-51 (2017). https://doi.org/10.1016/j.cpet.2016.08.001

5. A.H. Ashok, Y. Mizuno, O.D. Howes, Tobacco smoking and dopaminergic function in humans: a meta-analysis of molecular imaging studies. Psychopharmacology 236(4), 1119-1129 (2019). https://doi.org/10.1007/s00213-019-05196-1

6. M.K. Mahata, H. Bae, K.T. Lee, Upconversion luminescence sensitized pH-nanoprobes. Molecules 22(12), 2064 (2017). https://doi.org/10.3390/molecules22122064

7. H. Bi, F. He, Y. Dai, J. Xu, Y. Dong et al., Quad-model imaging-guided high-efficiency phototherapy based on upconversion nanoparticles and $\mathrm{ZnFe}_{2} \mathrm{O}_{4}$ integrated graphene oxide. Inorg. Chem. 57(16), 9988-9998 (2018). https://doi. org/10.1021/acs.inorgchem.8b01159

8. C. Liu, Z. Gao, J. Zeng, Y. Hou, F. Fang et al., Magnetic/ upconversion fluorescent $\mathrm{NaGdF} 4: \mathrm{Yb}$, Er nanoparticle-based dual-modal molecular probes for imaging tiny tumors in vivo. ACS Nano 7(8), 7227-7240 (2013). https://doi.org/10.1021/ nn4030898

9. X. Ai, Z. Wang, H. Cheong, Y. Wang, R. Zhang et al., Multispectral optoacoustic imaging of dynamic redox correlation and pathophysiological progression utilizing upconversion nanoprobes. Nat. Commun. 10(1), 1087 (2019). https://doi. org/10.1038/s41467-019-09001-7

10. S. Qiu, J. Zeng, Y. Hou, L. Chen, J. Ge et al., Detection of lymph node metastasis with near-infrared upconversion luminescent nanoprobes. Nanoscale 10(46), 21772-21781 (2018). https://doi.org/10.1039/c8nr05811c

11. J. Gallo, I.S. Alam, J. Jin, Y.J. Gu, E.O. Aboagye, W.T. Wong, N.J. Long, PET imaging with multimodal upconversion nanoparticles. Dalton Trans. 43(14), 5535-5545 (2014). https://doi. org/10.1039/c3dt53095g

12. Z. Chen, P. Zhao, Z. Luo, M. Zheng, H. Tian et al., Cancer cell membrane-biomimetic nanoparticles for homologoustargeting dual-modal imaging and photothermal therapy. ACS Nano 10(11), 10049-10057 (2016). https://doi.org/10.1021/ acsnano.6b04695

13. F.F. An, H. Kommidi, N. Chen, R. Ting, A conjugate of pentamethine cyanine and $18 \mathrm{~F}$ as a positron emission 
tomography/near-infrared fluorescence probe for multimodality tumor imaging. Int. J. Mol. Sci. 18(6), 18061214 (2017). https://doi.org/10.3390/ijms18061214

14. H. Dong, S.R. Du, X.Y. Zheng, G.M. Lyu, L.D. Sun, Lanthanide nanoparticles: from design toward bioimaging and therapy. Chem. Rev. 115(19), 10725-10815 (2015). https:// doi.org/10.1021/acs.chemrev.5b00091

15. L. Rao, Q.F. Meng, L.L. Bu, B. Cai, Q. Huang et al., Erythrocyte membrane-coated upconversion nanoparticles with minimal protein adsorption for enhanced tumor imaging. ACS Appl. Mater. Interfaces 9(3), 2159-2168 (2017). https ://doi.org/10.1021/acsami.6b14450

16. L. Rao, L.L. Bu, B. Cai, J.H. Xu, A. Li et al., Cancer cell membrane-coated upconversion nanoprobes for highly specific tumor imaging. Adv. Mater. 28(18), 3460-3466 (2016). https://doi.org/10.1002/adma.201506086

17. A. Soufer, L.A. Baldassarre, The role of cardiac magnetic resonance imaging to detect cardiac toxicity from cancer therapeutics. Curr. Treat Options Cardiovasc Med. 21(6), 28 (2019). https://doi.org/10.1007/s11936-019-0732-5

18. M. González-Béjar, L. Francés-Soriano, J. Pérez-Prieto, Upconversion nanoparticles for bioimaging and regenerative medicine. Front. Bioeng. Biotechnol. 4, 47 (2016). https ://doi.org/10.3389/fbioe.2016.00047

19. F.M. Goñi, The basic structure and dynamics of cell membranes: an update of the Singer-Nicolson model. Biochim. Biophys. Acta 1838(6), 1467-1476 (2014). https://doi. org/10.1016/j.bbamem.2014.01.006

20. M. Gao, C. Liang, X. Song, Q. Chen, Q. Jin, C. Wang, Z. Liu, Erythrocyte-membrane-enveloped perfluorocarbon as nanoscale artificial red blood cells to relieve tumor hypoxia and enhance cancer radiotherapy. Adv. Mater. 29(35), 1701429 (2017). https://doi.org/10.1002/adma.201701429

21. L. Rao, W. Wang, Q.F. Meng, M. Tian, B. Cai et al., A biomimetic nanodecoy traps zika virus to prevent viral infection and fetal microcephaly development. Nano Lett. 19(4), 2215-2222 (2019). https://doi.org/10.1021/acs.nanol ett. 8 b03913

22. C.M. Hu, L. Zhang, S. Aryal, C. Cheung, R.H. Fang, L. Zhang, Erythrocyte membrane-camouflaged polymeric nanoparticles as a biomimetic delivery platform. Proc. Natl. Acad. Sci. U.S.A. 108(27), 10980-10985 (2011). https:// doi.org/10.1073/pnas.1106634108

23. L. Rao, B. Cai, L.L. Bu, Q.Q. Liao, S.S. Guo, X.Z. Zhao, W.F. Dong, W. Liu, Microfluidic electroporation-facilitated synthesis of erythrocyte membrane-coated magnetic nanoparticles for enhanced imaging-guided cancer therapy. ACS Nano 11(4), 3496-3505 (2017). https://doi.org/10.1021/ acsnano.7b00133

24. C.M. Hu, R.H. Fang, K.C. Wang, B.T. Luk, S. Thamphiwatana et al., Nanoparticle biointerfacing by platelet membrane cloaking. Nature 526(7571), 118-121 (2015). https://doi. org/10.1038/nature15373

25. L. Rao, L.L. Bu, L. Ma, W. Wang, H. Liu et al., Plateletfacilitated photothermal therapy of head and neck squamous cell carcinoma. Angew. Chem. Int. Ed. 57(4), 986-991 (2018). https://doi.org/10.1002/anie.201709457

26. M. Ying, J. Zhuang, X. Wei, X. Zhang, Y. Zhang et al., Remote-loaded platelet vesicles for disease-targeted delivery of therapeutics. Adv. Funct. Mater. 28(22), 1801032 (2018). https://doi.org/10.1002/adfm.201801032

27. D. Dehaini, X. Wei, R.H. Fang, S. Masson, P. Angsantikul et al., Erythrocyte-platelet hybrid membrane coating for enhanced nanoparticle functionalization. Adv. Mater. 29(16), 1606209 (2017). https://doi.org/10.1002/ adma.201606209

28. R.H. Fang, C.M. Hu, B.T. Luk, W. Gao, J.A. Copp, Y. Tai, D.E. O'Connor, L. Zhang, Cancer cell membranecoated nanoparticles for anticancer vaccination and drug delivery. Nano Lett. 14(4), 2181-2188 (2014). https://doi. org/10.1021/nl500618u

29. S.Y. Li, H. Cheng, B.R. Xie, W.X. Qiu, J.Y. Zeng et al., Cancer cell membrane camouflaged cascade bioreactor for cancer targeted starvation and photodynamic therapy. ACS Nano 11(7), 7006-7018 (2017). https://doi.org/10.1021/ acsnano.7b02533

30. T.M. Saba, Physiology and physiopathology of the reticuloendothelial system. Arch. Intern. Med. 126(6), 1031-1052 (1970)

31. Y.N. Zhang, W. Poon, A.J. Tavares, I.D. McGilvray, W.C.W. Chan, Nanoparticle-liver interactions: cellular uptake and hepatobiliary elimination. J. Control. Release 240, 332-348 (2016). https://doi.org/10.1016/j.jconrel.2016.01.020

32. N. Zeng, Q. Hu, Z. Liu, X. Gao, R. Hu et al., Preparation and characterization of paclitaxel-loaded DSPE-PEG-liquid crystalline nanoparticles (LCNPs) for improved bioavailability. Int. J. Pharm. 424(1-2), 58-66 (2012). https://doi. org/10.1016/j.ijpharm.2011.12.058

33. W.J. McBride, R.M. Sharkey, H. Karacay, C.A. D’Souza, E.A. Rossi et al., A novel method of $18 \mathrm{~F}$ radiolabeling for PET. J. Nucl. Med. 50(6), 991-998 (2009). https://doi. org/10.2967/jnumed.108.060418

34. H.J. Jeong, R.J. Yoo, J.K. Kim, M.H. Kim, S.H. Park et al., Macrophage cell tracking PET imaging using mesoporous silica nanoparticles via in vivo bioorthogonal F-18 labeling. Biomaterials 199, 32-39 (2019). https://doi.org/10.1016/j. biomaterials.2019.01.043

35. L. Rao, G.T. Yu, Q.F. Meng, L.L. Bu, R. Tian et al., Cancer cell membrane-coated nanoparticles for personalized therapy in patient-derived xenograft models. Adv. Funct. Mater. 28(51), 1905671 (2019). https://doi.org/10.1002/ adfm. 201905671

36. L. Xu, F. Gao, F. Fan, L. Yang, Platelet membrane coating coupled with solar irradiation endows a photodynamic nanosystem with both improved antitumor efficacy and undetectable skin damage. Biomaterials 159, 59-67 (2018). https:// doi.org/10.1016/j.biomaterials.2017.12.028

37. J.O. Martinez, R. Molinaro, K.A. Hartman, C. Boada, R. Sukhovershin et al., Biomimetic nanoparticles with enhanced affinity towards activated endothelium as versatile 
tools for theranostic drug delivery. Theranostics 8(4), 11311145 (2018). https://doi.org/10.7150/thno.22078

38. H. Cao, Z. Dan, X. He, Z. Zhang, H. Yu, Q. Yin, Y. Li, Liposomes coated with isolated macrophage membrane can target lung metastasis of breast cancer. ACS Nano 10(8), 7738-7748 (2016). https://doi.org/10.1021/acsnano.6b031 48
39. C. Gao, Z. Lin, B. Jurado-Sánchez, X. Lin, Z. Wu, Q. He, Stem cell membrane-coated nanogels for highly efficient in vivo tumor targeted drug delivery. Small 12(30), 4056-4062 (2016). https://doi.org/10.1002/smll.201600624 